\title{
Prosthesis size and long-term survival after aortic valve replacement
}

\author{
Eugene H. Blackstone, $\mathrm{MD}^{\mathrm{a}, \mathrm{b}}$ \\ Delos M. Cosgrove, $\mathrm{MD}^{\mathrm{a}}$ \\ W. R. Eric Jamieson, $M^{C}$ \\ Nancy J. Birkmeyer, $\mathrm{PhD}^{\mathrm{d}}$ \\ John H. Lemmer, Jr, MD \\ D. Craig Miller, $\mathrm{MD}^{f}$ \\ Eric G. Butchart, FRCS ${ }^{g}$ \\ Giulio Rizzoli, MD ${ }^{\mathrm{h}}$ \\ Magdi Yacoub, MDi \\ Akiko Chai, MS
}

From the Departments of Thoracic and Cardiovascular Surgery and Biostatistics and Epidemiology, ${ }^{\mathrm{b}}$ The Cleveland Clinic Foundation, Cleveland, Ohio, The University of British Columbia, ${ }^{\mathrm{c}}$ Vancouver, British Columbia, Canada, Dartmouth Medical School, ${ }^{\mathrm{d}}$ Dartmouth-Hitchcock Medical Center, Lebanon, NH, Northwest Surgical Associates, ${ }^{e}$ Portland, Ore, Stanford University, ${ }^{\mathrm{f}}$ Stanford, Calif, University Hospital, ${ }^{\mathrm{g}}$ Cardiff, United Kingdom, Instituto Chirurgia Cardiovascolare, ${ }^{\mathrm{h}}$ University of Padova, Padova, Italy, Harefield Hospital, ${ }^{i}$ London, United Kingdom, and Edwards Lifesciences Corporation, ${ }^{\mathrm{j}}$ Irvine, Calif.

Read at the Eightieth Annual Meeting of The American Association for Thoracic Surgery, Toronto, Ontario, Canada, April 30-May 3, 2000.

Received for publication April 28, 2000; revisions received Nov 27, 2002; accepted for publication Feb 26, 2003.

Address for reprints: Eugene H. Blackstone, MD, The Cleveland Clinic Foundation, 9500 Euclid Ave, Desk F25, Cleveland, OH 44195 (E-mail: blackse@ @ccf.org).

J Thorac Cardiovasc Surg 2003;126:783-96

Copyright $\odot 2003$ by The American Association for Thoracic Surgery

$0022-5223 / 2003 \$ 30.00+0$

doi:10.1016/S0022-5223(03)00591-9
Objective: This study was undertaken to quantify the relationship between prosthesis size adjusted for patient size (prosthesis-patient size) and long-term survival after aortic valve replacement.

Methods: Data from nine representative sources on 13,258 aortic valve replacements provided 69,780 patient-years of follow-up (mean $5.3 \pm 4.7$ years), with reliable survival estimates to 15 years. Prostheses included 5757 stented porcine xenografts, 3198 stented bovine pericardial xenografts, 3583 mechanical valves, and 720 allografts. Manufacturers' labeled prosthesis size was $19 \mathrm{~mm}$ or smaller in 1109 patients. Expressions of prosthesis-patient size assessed were indexed internal prosthesis orifice area (in centimeters squared per square meter of body surface area) and standardized internal prosthesis orifice size ( $Z$, the number of SDs from mean normal native aortic valve size). Multivariable hazard domain analysis with balancing score and risk factor adjustment quantified the association of prosthesis-patient size with survival.

Results: Prosthesis-patient size down to at least $1.1 \mathrm{~cm}^{2} / \mathrm{m}^{2}$ or $-3 \mathrm{Z}$ did not adversely affect intermediate- or long-term survival $(P>.2)$. However, 30-day mortality increased $1 \%$ to $2 \%$ when indexed orifice area fell below $1.2 \mathrm{~cm}^{2} / \mathrm{m}^{2}(P$ $=.002)$ or standardized orifice size fell below $-2.5 Z(P=.0003)$. The increased early risk affected fewer than $1 \%$ of patients receiving bioprostheses but about $25 \%$ of those receiving mechanical devices.

Conclusions: Aortic prosthesis-patient size down to $1.1 \mathrm{~cm}^{2} / \mathrm{m}^{2}$ or $-3 Z$ did not reduce intermediate- or long-term survival after aortic valve replacement. However, patient-prosthesis size under $1.2 \mathrm{~cm}^{2} / \mathrm{m}^{2}$ or $-2.5 \mathrm{Z}$ was associated with a $1 \%$ to $2 \%$ increase in 30-day mortality. Prosthesis-patient sizes this small or smaller were rarely implanted in patients receiving bioprostheses.

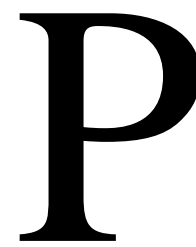

rosthesis-patient size mismatch is a clinical entity that occurs occasionally after aortic valve replacement (AVR). ${ }^{1,2}$ Its mechanism is high transprosthesis energy loss ${ }^{3}$ that increases left ventricular work, reduces left ventricular mass regression, and produces symptoms of aortic stenosis, with presumed shortening of lifespan. This study addresses the impact of prosthesis-patient size on time-related survival after AVR. 
TABLE 1. Sources of individual patient data

\begin{tabular}{llr}
\hline Source & Location & Inclusive dates* $^{*}$ \\
\hline The Cleveland Clinic Foundation & Cleveland, Ohio & $5 / 1975-6 / 1999$ \\
University of British Columbia & Vancouver, British Columbia, Canada & $3 / 1976-7 / 1996$ \\
Northern New England & Lebanon, NH† & $9 / 1989-1 / 1997$ \\
$\quad$ Cardiovascular Disease Study Group & & 2,046 \\
Northwest Surgical Associates & Portland, Oreł & 1,928 \\
Stanford University & Stanford, Calif & $3 / 1976-12 / 1998$ \\
University Hospital & Cardiff, UK & $8 / 1971-3 / 1990$ \\
Instituto Chirurgia Cardiovascolore, & Padova, Italy & $2 / 1980-4 / 1994$ \\
$\quad$ University of Padova & & $3 / 1970-12 / 1997$ \\
Harefield Hospital & London, UK & 1,164 \\
Edwards Lifesciences Corporation & Irvine, Calif & 729 \\
\hline Total & & 692 \\
\end{tabular}

${ }^{*}$ Rounded to nearest month.

tA multi-institutional collaboration.

$\ddagger$ A multi-institutional collaboration of Health Data Research, Inc, Portland, Ore.

The study has two unique features. First, it uses an analytic method that permits independent assessment of the association of prosthesis-patient size with long-, intermediate-, and short-term survivals. Second, it uses a large multiinstitutional group of patients to achieve sufficient statistical power to make these assessments. Purposes of the investigation were to quantify the relationship of prosthesis-patient size to long-, intermediate-, and short-term survivals and from this relationship to develop a clinically useful algorithm for identifying a prosthesis size below which survival might be affected.

\section{Patients and Methods}

\section{Patients}

Individual patient data on 13,258 AVRs were assembled from nine sources (Table 1). Included were adults at least 18 years old for whom prosthesis type, model, and labeled size were recorded. Excluded were patients with a preexisting valve prosthesis in a location other than aortic, those undergoing a multiple valve operation, those with native or prosthetic valve endocarditis, those undergoing emergency AVR, and those undergoing concomitant procedures other than coronary artery bypass grafting. Patients undergoing aortic root enlargement were not excluded. Half the operations were performed before 1990 (Table 1).

Data with identifiers removed were assembled from existing registries and clinical research databases. Variables available across all sources are listed in Appendix 1. This combination of individual patient data from multiple sources has been termed a meta-analysis of individual patient data. ${ }^{4}$

\section{Prostheses}

Prostheses were of four varieties: stented porcine xenografts $(\mathrm{n}=$ 5757, designated porcine), stented bovine pericardial xenografts (n $=3198$, designated pericardial $)$, mechanical devices $(\mathrm{n}=3583$, of which 2125 were bileaflet and 1458 were monoleaflet), and allografts $(n=720)$. Patient characteristics varied according to variety of prosthesis received (Tables $2 \mathrm{~A}$ and $2 \mathrm{~B}$ ).

\section{Prosthesis-Patient Size}

Prosthesis size was normalized to patient size by relating geometric dimensions of the prosthesis to body surface area (BSA). We call this prosthesis-patient size. We have avoided the term prosthesis-patient mismatch because we made no a priori assumptions about what this might mean; rather, we examined the entire range of prosthesis-patient size in relation to survival.

Prosthesis size was defined in terms of geometric dimensions of prostheses, not in vitro or in vivo functional dimensions. These properties included the manufacturer's labeled size (in millimeters), which refers inconsistently to diameter of external sewing ring (mechanical prostheses), mounting ring (stented xenografts), or internal orifice (allografts), and the geometric internal orifice diameter (in millimeters), a consistent physical dimension (Appendix Table 1). ${ }^{5}$ They did not include patient's tissue annulus diameter, a proposed ISO standard (ISO/CD 5840 working decrement) that was not recorded in any source. Patient size was represented by BSA, calculated from height and weight. ${ }^{6}$

Prosthesis-patient size was expressed in two ways: as indexed orifice area (in square centimeters per square meter), calculated from prosthesis internal orifice diameter assuming a circular orifice shape and patient's BSA, and as standardized orifice size $(Z)$, the number of SDs by which internal orifice diameter deviated from mean normal native aortic "annulus" (left ventriculoaortic junction) diameter for the patient's BSA (see Table 2B). ${ }^{7}$ Distributions of these expressions of prosthesis-patient size, stratified by prosthesis variety, are shown in Figure 1.

\section{End Point}

Study end point was all-cause mortality, including in-hospital mortality. ${ }^{8}$ A total of 69,780 patient-years of follow-up were available for analysis (mean $5.3 \pm 4.7$ years); 2427 patients (18\%) were followed 10 years or longer, and 498 (4\%) were followed more than 15 years (as long as 27 years).

\section{Data Analysis}

Survival estimates. Overall survivals were $95.8 \%$ at 30 days and $91 \%, 79 \%, 58 \%$, and $37 \%$ at $1,5,10$, and 15 years (Figure 2, 
TABLE 2A. Characteristics of patients and their operations according to variety of prosthesis (categorical variables)

\begin{tabular}{|c|c|c|c|c|c|c|c|c|}
\hline \multirow[b]{2}{*}{ Variable } & \multicolumn{2}{|c|}{$\begin{array}{c}\text { Porcine } \\
(n=5757)\end{array}$} & \multicolumn{2}{|c|}{$\begin{array}{l}\text { Pericardial } \\
(\mathrm{n}=3198)\end{array}$} & \multicolumn{2}{|c|}{$\begin{array}{c}\text { Mechanical } \\
(n=3583)\end{array}$} & \multicolumn{2}{|c|}{$\begin{array}{c}\text { Allograft } \\
(n=720)\end{array}$} \\
\hline & No. & $\%$ & No. & $\%$ & No. & $\%$ & No. & $\%$ \\
\hline Men & 4187 & 73 & 2006 & 63 & 2402 & 67 & 504 & 70 \\
\hline \multicolumn{9}{|l|}{ New York Heart Association functional class } \\
\hline I & $383 / 5412$ & 7 & $274 / 2905$ & 9 & $286 / 2808$ & 10 & $58 / 703$ & 8 \\
\hline II & 1638 & 30 & 1277 & 44 & 1217 & 43 & 202 & 29 \\
\hline III & 2782 & 51 & 924 & 32 & 1039 & 37 & 366 & 52 \\
\hline IV & 609 & 11 & 430 & 15 & 266 & 9 & 77 & 11 \\
\hline Previous AVR & 432 & 8 & 494 & 15 & 456 & 13 & 32 & 4 \\
\hline Aortic stenosis (greater than mild) & $4055 / 5737$ & 71 & $2579 / 3024$ & 85 & $2387 / 3363$ & 71 & $502 / 709$ & 71 \\
\hline Aortic regurgitation (greater than mild) & $1367 / 5494$ & 25 & $939 / 2819$ & 33 & $1512 / 3237$ & 47 & $332 / 694$ & 48 \\
\hline Concomitant coronary artery bypass grafting & 2184 & 38 & 1662 & 52 & 1101 & 31 & 115 & 16 \\
\hline
\end{tabular}

For differences among groups $\left(\chi^{2}\right.$ test), all $P<.0001$. When there are missing values, the denominator is given after the number.

TABLE 2B. Characteristics of patients and their prostheses according to variety of prosthesis (continuous variables)

\begin{tabular}{|c|c|c|c|c|c|c|c|c|}
\hline \multirow[b]{2}{*}{ Variable } & \multicolumn{2}{|c|}{ Porcine } & \multicolumn{2}{|c|}{ Pericardial } & \multicolumn{2}{|c|}{ Mechanical } & \multicolumn{2}{|c|}{ Allograft } \\
\hline & No. & Mean \pm SD & No. & Mean \pm SD & No. & Mean \pm SD & No. & Mean \pm SD \\
\hline Age (y) & 5757 & $65 \pm 12.9$ & 3198 & $72 \pm 8.9$ & 3583 & $60 \pm 12.1$ & 720 & $51 \pm 14.0$ \\
\hline Body surface area $\left(\mathrm{m}^{2}\right)$ & 4053 & $1.86 \pm 0.22$ & 3161 & $1.90 \pm 0.23$ & 3341 & $1.91 \pm 0.24$ & 719 & $1.86 \pm 0.22$ \\
\hline Labeled size (mm) & 5757 & $24 \pm 2.6$ & 3198 & $22 \pm 2.2$ & 3583 & $23 \pm 2.6$ & 720 & $23 \pm 1.94$ \\
\hline Orifice diameter (mm) & 5757 & $22 \pm 2.4$ & 3198 & $21 \pm 2.2$ & 3583 & $18 \pm 2.3$ & 720 & $23 \pm 1.94$ \\
\hline Indexed orifice area $\left(\mathrm{cm}^{2} / \mathrm{m}^{2}\right)$ & 4053 & $2.0 \pm 0.42$ & 3161 & $1.89 \pm 0.37$ & 3341 & $1.44 \pm 0.35$ & 719 & $2.2 \pm 0.43$ \\
\hline Standardized orifice size $(Z)^{*}$ & 4053 & $0.0 \pm 1.11$ & 3161 & $-0.28 \pm 1.03$ & 3341 & $-1.82 \pm 1.26$ & 719 & $0.62 \pm 1.04$ \\
\hline
\end{tabular}

For differences among groups (parametric and nonparametric tests), all $P<.0001$.

* $Z$ score represents the number of SDs by which the internal prosthesis orifice size differs from the predicted mean normal native aortic valve size for that patient's body surface area.

A). Instantaneous risk of death peaked immediately after operation, fell rapidly during the first 6 postoperative months, and then rose steadily (Figure 2, B). These represent three additive hazard phases labeled early, constant, and late. To determine the independent influence of prosthesis-patient size on long-, intermediate-, and short-term survivals, a multiphase hazard decomposition method was used (available for use with the SAS system at http://www. clevelandclinic.org/heartcenter/hazard). Each hazard phase (Figure $2, B$ ) incorporated an independent set of risk factors, permitting quantification of the effect of prosthesis-patient size within each time frame determined by the data themselves, not arbitrarily, without assuming proportional hazards. ${ }^{9}$

Risk adjustment. All variables listed in Appendix 1 were included in each hazard phase of all multivariable models, a saturated model risk-adjustment strategy (Appendix 2). ${ }^{10}$ However, even saturated multivariable models may not account completely for confounding between selection of prosthesis size for a patient and outcome. Therefore a balancing score for each expression of prosthesis-patient size was constructed and included as a further adjustment in each hazard phase (Appendix 2). ${ }^{11,12}$

Prosthesis-patient size and survival. Separate analyses were performed of the relation of risk-adjusted mortality to continuous values of indexed orifice area and standardized orifice size $(Z)$. The specific linearizing transformations of scale for these (and other continuous variables) for each hazard phase were selected by bootstrap bagging (Appendix 2). ${ }^{13,14}$ Whenever computatively possible, effects of both large and small prosthesis-patient size were estimated (Appendix 3).

\section{Clinical algorithm}

An internal prosthesis orifice diameter was calculated across the spectrum of BSA below which increased risk of mortality might be anticipated. For this, formulas for indexed orifice area and standardized orifice size were rearranged and solved at fixed values of prosthesis-patient size.

\section{Presentation}

Survival curves are presented with both parametric and KaplanMeier estimates. Confidence limits are asymmetric and equivalent to $1 \mathrm{SE}(68 \%)$. To illuminate multivariable findings, nomograms were constructed by solving the multivariable equations for a 70 -year-old woman of $1.9 \mathrm{~m}^{2}$ BSA with aortic stenosis, in New York Heart Association functional class III, and undergoing primary isolated AVR in the current era.

\section{Results}

Prosthesis Size and Non-Risk-Adjusted Survival

Small, nonsystematic survival differences were observed with respect to both indexed orifice area (Figure 3) and standardized orifice size (Figure 4). Systematic survival decrements were found with decreasing labeled size (Ap- 

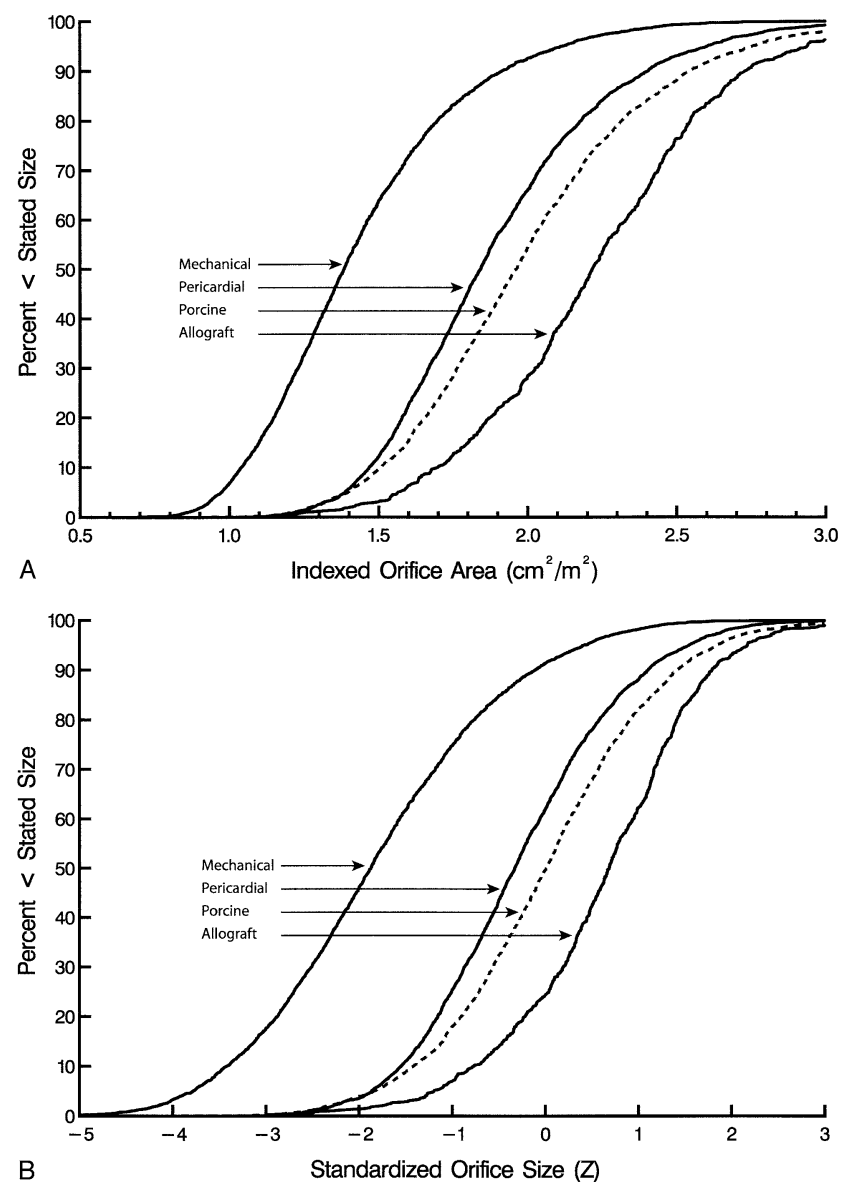

Figure 1. Cumulative distribution of physical internal valve orifice dimension referenced to patients' BSA (prosthesis-patient size). Distribution is stratified according to variety of prosthesis: mechanical, stented bovine pericardial (pericardial), stented porcine xenograft (porcine), and allograft. For orientation, median size is value on horizontal axis that corresponds to value of $\mathbf{5 0} \%$ on vertical axis; half the sizes were smaller than this and half larger. Value on horizontal axis corresponding to $10 \%$ on vertical axis is the 10th percentile, meaning that $10 \%$ of valves were smaller than this and $\mathbf{9 0} \%$ larger. A, Indexed orifice area. B, Standardized orifice size.

pendix Figure 1, A) and according to variety of prosthesis (Appendix Figure 1, B). However, these differences were largely accounted for by differing patient characteristics according to prosthesis size and variety (Table $2 \mathrm{~B}$ and Appendix 2).

\section{Prosthesis-Patient Size and Risk-Adjusted Survival}

Long- and intermediate-term survivals. After adjustment for balancing score and patient, operative, institutional, and prosthesis model variables (Appendices 2 and 3 ), small prosthesis-patient size down to at least 1.1 $\mathrm{cm}^{2} / \mathrm{m}^{2}$ and 3 SDs below normal $(-3 \mathrm{Z})$ did not decrease
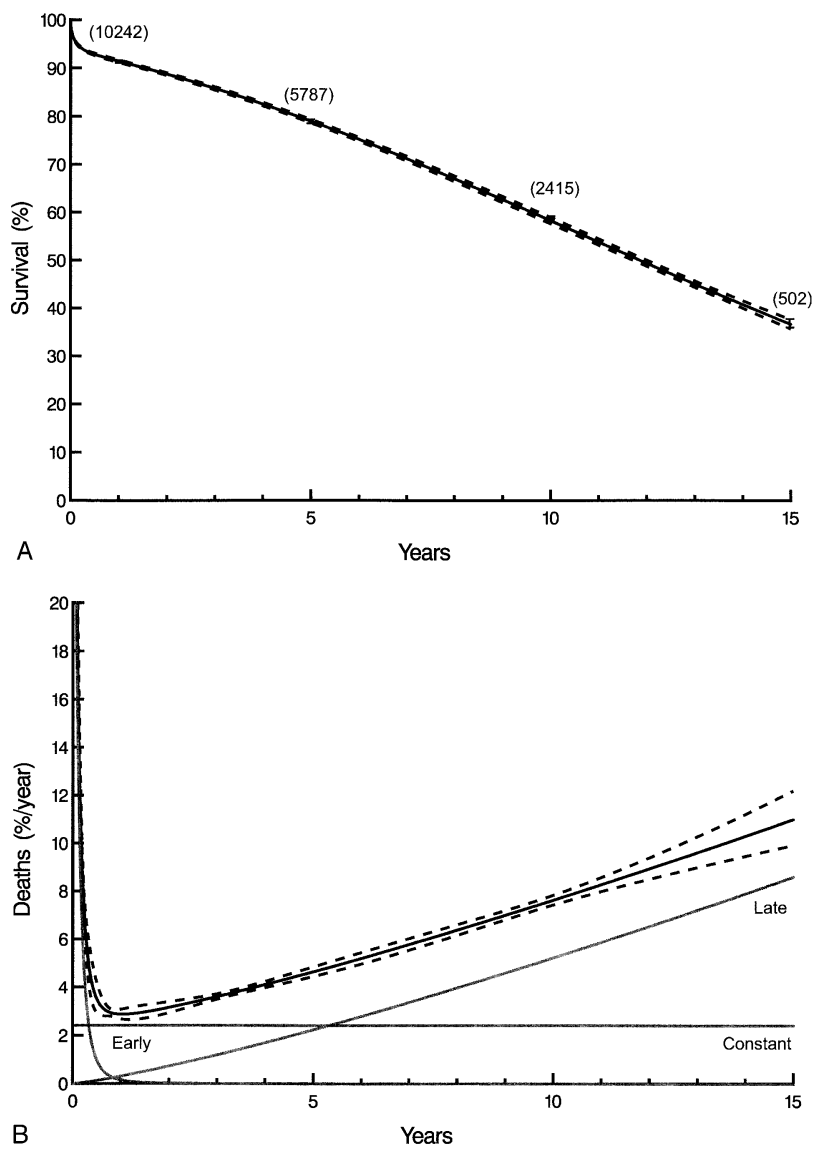

Figure 2. Overall survival after AVR. A, Survival. Parametric estimates (solid line) are enclosed within confidence limits equivalent to $1 \mathrm{SE}(68 \%)$. Numbers in parentheses represent numbers of patients still being followed at 1, 5, 10, and 15 years. Faintly visible at these same intervals are vertical bars representing confidence limits for corresponding nonparametric Kaplan-Meier estimates. B, Hazard function (instantaneous risk of death). Solid curve enclosed within asymmetric $68 \%$ confidence limits represents parametric overall hazard estimates. Individual hazard components are labeled early, constant, and late; they sum to yield overall hazard. Rapidly falling early phase of risk lasted approximately 6 months (short-term survival), was dominated by operative mortality, and had effective statistical power of 774 events. Constant hazard phase across all time dominated between 6 months and 5 years (intermediate-term survival) and had statistical power of 1654 events. Late hazard phase, rising steadily from time zero, dominated beyond 5 years (late-term survival) and had statistical power of 1470 events. Variables in multivariable analyses modulated area beneath early hazard phase, raised or lowered constant hazard, and tilted late hazard component.

intermediate-term (constant hazard phase) or long-term (late hazard phase) survival (Table 3 and Appendix 3). The confidence limits of the continuous relation of prosthesis-patient size to survival overlapped across the 

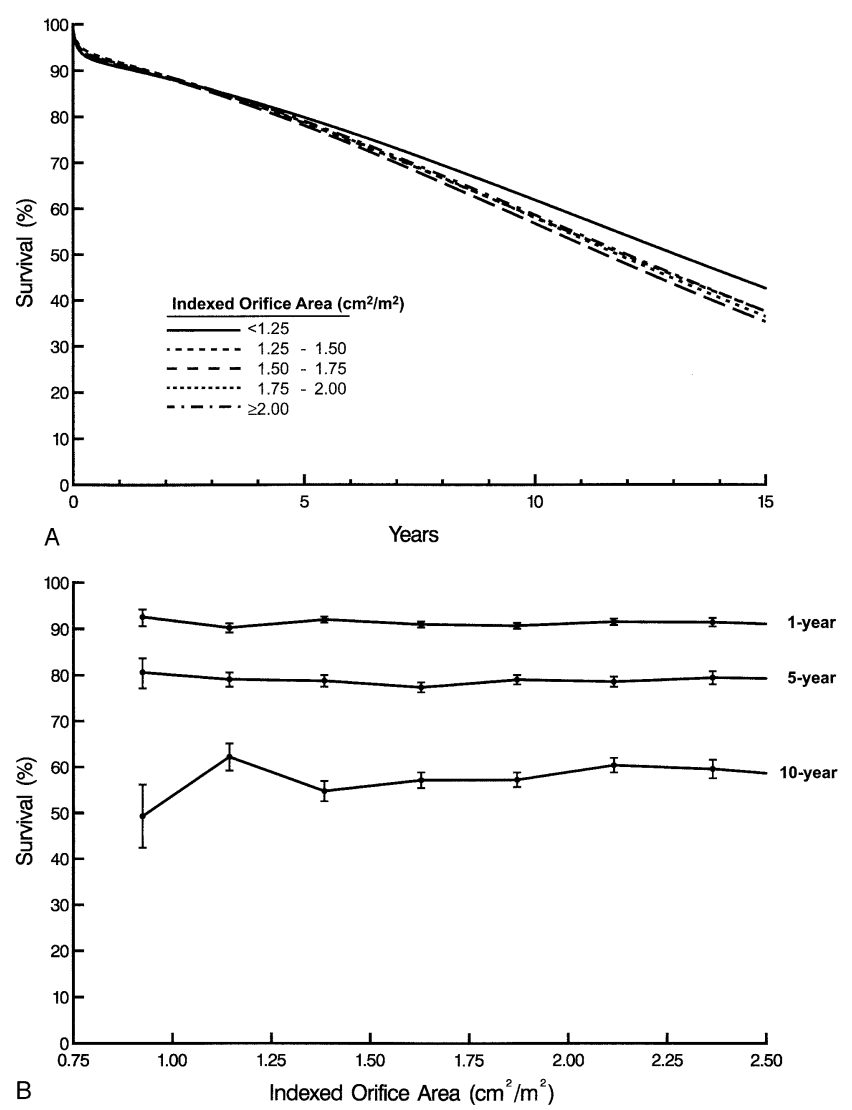

Figure 3. Non-risk-adjusted survival and indexed orifice area. A, Time-related survival stratified by indexed orifice area. B, Kaplan-Meier estimates of 1-, 5-, and 10-year survivals in finely grouped strata of indexed orifice area.

spectrum of prosthesis-patient size at 5, 10, and 15 years (Figure 5).

Short-term mortality. Mortality in the early hazard phase increased at the extreme of small prosthesis-patient size (Table 3). Compared with the most favorable risk, 30 -day mortality is predicted to increase $1 \%$ to $2 \%$ if indexed orifice area falls below $1.2 \mathrm{~cm}^{2} / \mathrm{m}^{2}$ (Figure $6, A$ ) or standardized orifice size falls below $-2.5 \mathrm{Z}$ (Figure 6, $B)$.

\section{Clinical Algorithm}

Prosthesis-patient size of $1.2 \mathrm{~cm}^{2} / \mathrm{m}^{2}$ or $-2.5 \mathrm{Z}$ may be considered thresholds for prosthesis-patient size mismatch with respect to early survival. Prosthesis-patient size rarely fell below these critical values in patients receiving bioprostheses (Figure 1); such sizes were more common among patients receiving mechanical prostheses.

By substituting either $1.2 \mathrm{~cm}^{2} / \mathrm{m}^{2}$ or $-2.5 \mathrm{Z}$ into their respective formulas, a simple nomogram reveals the internal orifice size of a prosthesis at these thresholds for any BSA (Figure 7). The nomogram can be used in the operating room
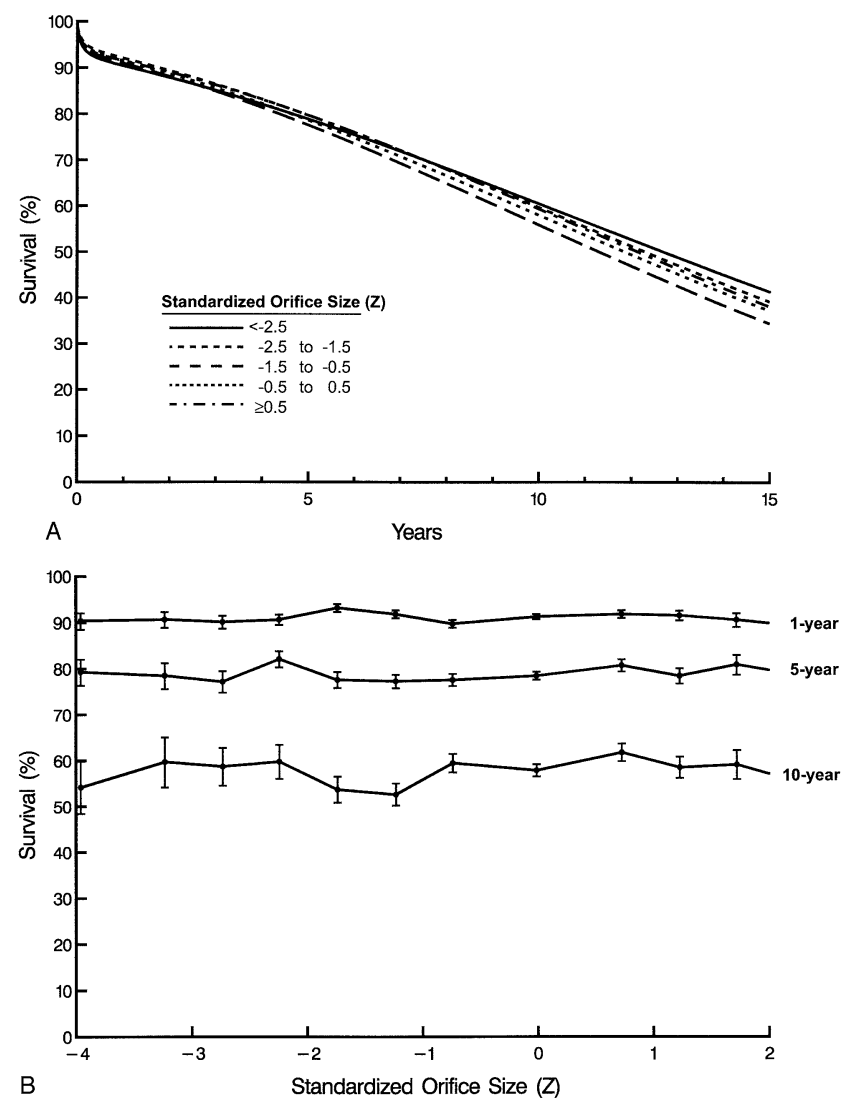

Figure 4. Non-risk-adjusted survival and standardized orifice size (Z). A, Time-related survival stratified by Z. B, Kaplan-Meier estimates of 1-, 5-, and 10-year survivals in finely grouped strata of $Z$.

by drawing a vertical line from a patient's BSA to the solid line and a horizontal line from there to the internal orifice diameter. Appendix Table A1 is then used to find the next largest labeled-size prosthesis that provides either indexed orifice area or standardized orifice size above these threshold values.

\section{Discussion}

Prosthesis-patient size mismatch leading to clinical symptoms and requiring reoperation is a reality, although much of the literature focuses on hemodynamics rather than clinical symptoms. ${ }^{1,2}$ It is also recognized that prosthetic aortic valves present more impedance to left ventricular outflow than do normal native valves. Thus, manufacturers have concentrated on increasing prosthesis hemodynamic efficiency (performance). It is therefore surprising that the principal finding of this study was a failure to detect small prosthesis-patient size as a risk factor for intermediate- or long-term survival, consistent with smaller single-institution studies and moderately large multi-institution studies. ${ }^{15-19}$ How can these results be explained when logic 
TABLE 3. Risk-adjusted association of prosthesis-patient size (as a continuous variable) with mortality

\begin{tabular}{|c|c|c|c|c|c|c|}
\hline \multirow[b]{2}{*}{ Variable } & \multicolumn{2}{|c|}{ Early hazard phase } & \multicolumn{2}{|c|}{ Constant hazard phase } & \multicolumn{2}{|c|}{ Late hazard phase } \\
\hline & Coefficient \pm SD & $P$ value & Coefficient \pm SD & $P$ value & Coefficient \pm SD & $P$ value \\
\hline \multicolumn{7}{|c|}{ Indexed orifice area $\left(\mathrm{cm}^{2} / \mathrm{m}^{2}\right)$} \\
\hline Smaller* & $0.90 \pm .29$ & .002 & $0.38 \pm 0.28$ & .18 & - & - \\
\hline Larger & - & - & - & - & $0.27 \pm 0.133$ & .05 \\
\hline \multicolumn{7}{|c|}{ Standardized orifice size (Z) } \\
\hline Smaller & $-0.189 \pm 0.052$ & .0003 & $-0.0086 \pm 0.0149$ & .6 & - & - \\
\hline Larger & $0.034 \pm 0.0096 \dagger$ & .0003 & - & - & $0.027 \pm 0.0125 \ddagger$ & .03 \\
\hline
\end{tabular}

All variables in Appendix Table 2 were included in these models, as were balancing scores in each hazard phase. Thus, the estimates are adjusted for all these factors. Dashes refer to lack of an effect with a coefficient that is assumed to be zero. In most cases, it was not computatively possible to include a transformation of scale that would quantify an effect.

*Inverse squared transformation, (1/indexed orifice area)2; although a negative coefficient sign is expected for "smaller" and a positive sign for "larger," indicating direction of effect, linearizing transforms such as this reverse the signs.

tExponential transformation, $\exp (Z)$.

¥Signed squared transformation, sign $(Z) \cdot Z^{2}$.

suggests that sustained elevated transprosthesis energy loss should translate into decreased long-term survival? ${ }^{20}$

First, the natural history of mild, fixed native aortic valve stenosis is unknown. Progressive aortic disease tends to become apparent in elderly persons; mild nonprogressive stenosis may be well tolerated. Second, patients who undergo AVR have lower long-term survival than an age-, sex-, and race-matched general population (Appendix Figure 2). ${ }^{6}$ Mortality is affected by complications of warfarin anticoagulation (particularly its variability ${ }^{21}$ ) among patients with mechanical devices and by reoperation for structural valve degeneration among those with biologic prostheses. Yet in this study and others, ${ }^{22}$ it has been difficult to demonstrate a survival difference according to prosthesis variety (Appendix 3). Thus, the multifactorial nature of reduced survival after AVR may mask subtle individual components of it, such as small prosthesis-patient size. Third, few prostheses, and almost no bioprostheses, had a prosthesis-patient size smaller than the $95 \%$ confidence limits of normal native human aortic valves $(-2 Z)$. Thus, AVR as practiced in centers represented in this study is such that prosthesis-patient size is rarely excessively small. ${ }^{23}$ Fourth, degenerative aortic valve stenosis is a disease of elderly patients with already limited lifespans. Although we searched for interactions of age with prosthesis-patient size and found none, elderly patients simply may not live long enough to manifest a survival decrement from small prosthesis-patient size. Fifth, the $1 \%$ to $2 \%$ increase in shortterm mortality found among patients with small prosthesispatient size may serve as a biologic selection process. However, our cohort of patients with such prostheses (1109 patients with a labeled size of $19 \mathrm{~mm}$ or smaller) was sufficiently large, short-term mortality sufficiently low, and survival sufficiently long to suggest that this is not an important explanation.

What seems to be secure information is that patients with particularly small prosthesis-patient size are exposed to a slight increase in short-term mortality, consistent with several reports. ${ }^{16,24-28}$ Pibarot and colleagues ${ }^{25}$ attribute increased early risk to poorer postoperative cardiac performance. However, most reports of increased early risk associated with small prostheses have not been well risk adjusted because of being underpowered. For example, small prostheses are preferentially used in elderly patients (Appendix Table 3), and this may confound interpretation of outcome (Appendix Figure 2). In this study, sufficient statistical power was available and an appropriate methodology was used to reliably examine short-term mortality.

This study does not resolve the dilemma of managing the small aortic root, at least with respect to short-term mortality. Some surgeons avoid inserting small prostheses, accepting the complexity and possible added risk of aortic root enlargement ${ }^{29,30}$; others, particularly when faced with an elderly patient with a small aortic root, insert a small prosthesis without an enlarging procedure. ${ }^{31}$ Subannular or supra-annular positioning of the prosthesis may permit size upgrading. Stentless prostheses are highly advocated; however, their internal orifice may be smaller than that of a similarly labeled-size stented pericardial prosthesis. ${ }^{32}$ These differing approaches to managing the small aortic root reflect differences of opinion regarding the adverse clinical impact of small prosthesis size.

\section{Issues}

At the time of its original presentation, in subsequent discussions of its findings, and among ourselves, this study raised several methodologic issues.

Statistical power and risk adjustment. Confounding reliable assessment of the relation of prosthesis size to mortality are differences in characteristics of patients receiving each size and variety of prosthesis, necessitating risk adjustment; inconsistencies between manufacturer's labeled size for various types of prosthesis, necessitating adoption of consistent expressions of prosthesis size; limitations of 

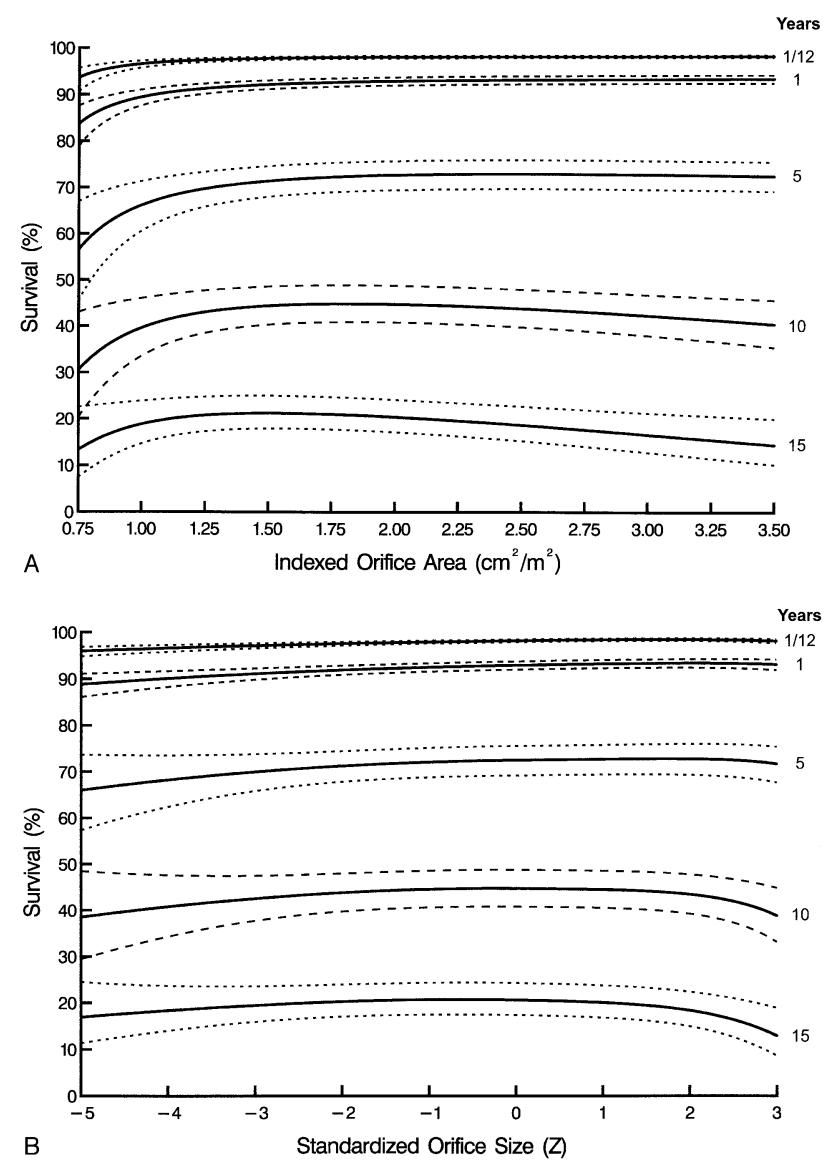

Figure 5. Magnitude and shape of effect of continuous prosthesis-patient size on 30-day and 1-, 5-, 10-, and 15-year survivals. Depictions are nomograms of multivariable equations solved for a typical patient with aortic stenosis (see Methods) with valve size varied. A, Indexed orifice area. B, Standardized orifice size.

single-institution studies, particularly regarding number of patients receiving small prostheses, necessitating a multiinstitutional study; and low operative mortality, necessitating a large study with a sufficient number of deaths to achieve adequate statistical power. By amassing a large AVR database with a sufficient number of events (3898 deaths), we were available to achieve statistical power to identify even a small survival impact of prosthesis-patient size and to localize it to a specific follow-up time frame while adjusting simultaneously for many important patient variables, device models, data sources, and selection factors.

Prosthesis size. Prosthesis size may be based on physical dimensions or functional performance. Physical dimensions include labeled size and internal orifice size. Because manufacturers' conventions for labeling prosthesis size differ among devices, we selected a common metric: geometric internal orifice diameter. ${ }^{5}$ Functional size includes in vitro and in vivo effective orifice areas
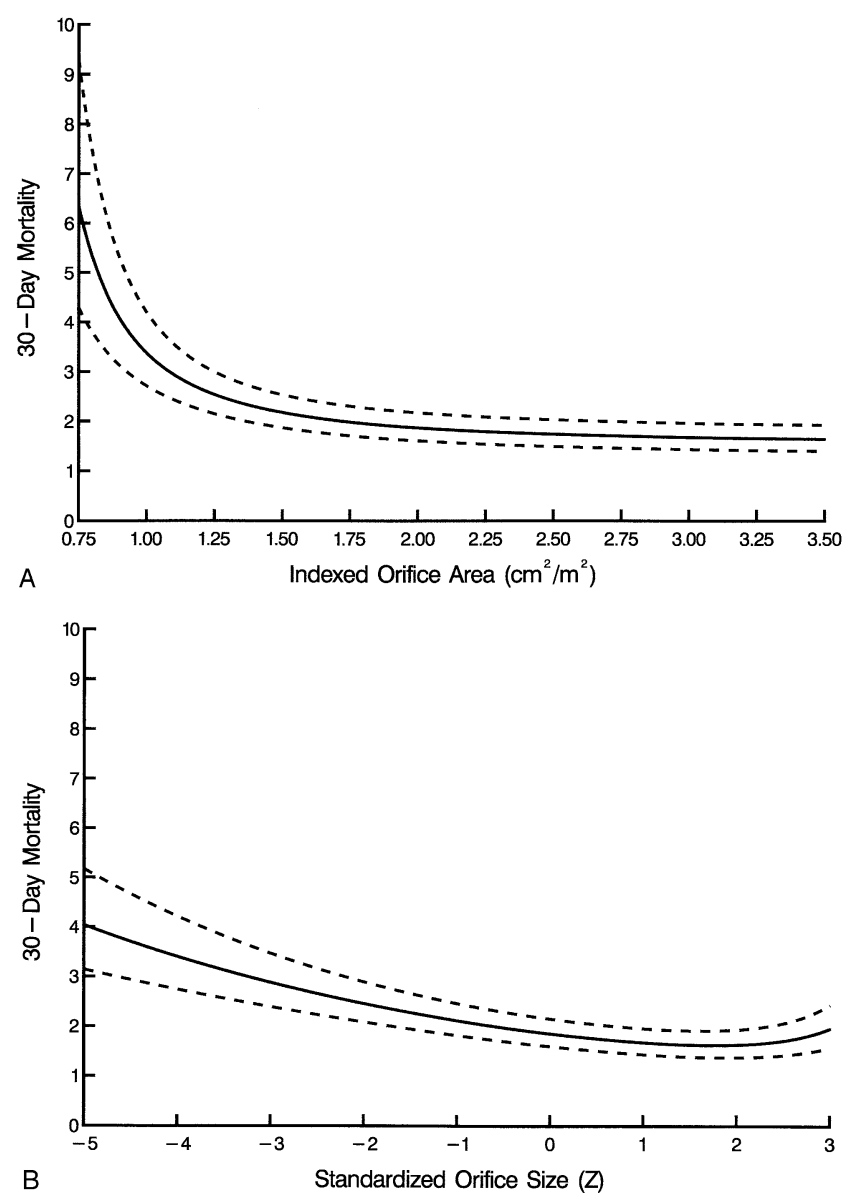

Figure 6. Magnitude and shape of effect of continuous prosthesis-patient size on 30-day mortality. Depictions are nomograms of multivariable equations solved for a typical patient with aortic stenosis (see Methods) with valve size varied. A, Indexed orifice area. B, Standardized orifice size.

(EOAs). The former may be static at a variety of steady flow rates or dynamic with a variety of pulsatile waveforms and flow rates ${ }^{33}$; the latter is estimated clinically under a range of incompletely controlled conditions in patients by echocardiography according to various formulas.

We have not included information about in vitro EOA, because methodology has been difficult to standardize and results are difficult to reproduce. We had no individual patient data on functional in vivo EOA. In vivo EOA varies from moment to moment with patient activity, ${ }^{34,35}$ cardiac output and blood pressure, and dynamics of the left ventricular outflow tract, as well as intrinsic prosthesis properties, although it is well correlated with geometric internal orifice area. ${ }^{34}$ It is therefore possible that one or more individual patients had functional prosthesis-patient size mismatch that we did not evaluate. However, in vivo EOA is unavailable at the time of selecting a prosthesis at AVR. 


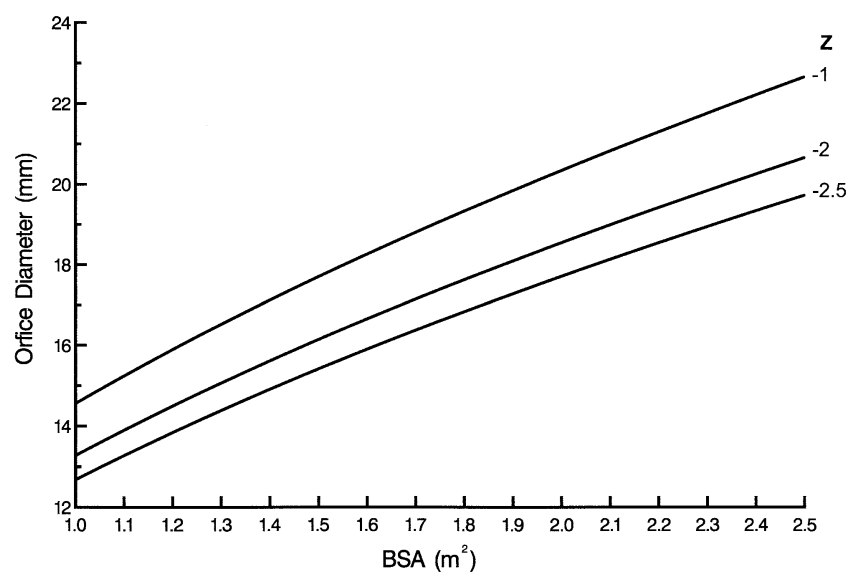

Figure 7. Minimum internal prosthesis orifice size necessary to achieve indexed orifice area of at least $-1\left(1.6 \mathrm{~cm}^{2} / \mathrm{m}^{2}\right),-2(1.3$ $\left.\mathrm{cm}^{2} / \mathrm{m}^{2}\right)$, and $-2.5\left(1.2 \mathrm{~cm}^{2} / \mathrm{m}^{2}\right) \mathrm{SDs}(Z)$ below mean normal aortic valve size.

Pibarot and colleagues ${ }^{36}$ and Dumesnil and coworkers ${ }^{34}$ have suggested that rather than using geometric prosthesis dimensions as a fixed reference for prosthesis size, a fixed referent value of in vivo EOA should be used, which they termed projected EOA. Referent values were obtained from informal meta-analysis of literature sources. To the extent that in vivo EOA differs importantly from a linear relation to geometric orifice area, substituting projected EOA for geometric size is advantageous. However, this strategy has several drawbacks: It suffers from flow dependency, large scatter in the data, rest versus exercise differences, and limited availability of data for each prosthesis size and model. Also, when fixed referent values are used for intraoperative decision making, they acquire the same limitations as the simpler geometric values used in this study. For intraoperative decision making, we therefore recommend using the relation of survival to prosthesis geometric orifice dimensions.

Patient size. Native aortic valve size is related to somatic growth, as is cardiac output. The most consistent allometric relationship, then, is BSA. ${ }^{6}$

Normalization. Normalization of any expression of prosthesis size can be made to body size. Use of indexed valve area assumes a linear relation between valve area and BSA, which is nearly, but not completely, accurate. ${ }^{6}$ Use of dimensionless standardized values $(Z)$ is based on the variability of native annulus size among similarly sized healthy individuals. Rimoldi and $\mathrm{Lev}^{37}$ introduced the idea that normality and abnormality can be expressed in terms of number of SDs away from normal size given a patient's cardiac structures measure. Thus, only $2.5 \%$ of the normal population have a valve size 2 SDs or more below mean normal size $(-2 Z)$. Both mean normal value and its SD are estimated by regression analysis of normal patient data. ${ }^{7}$
Then, given BSA and valve size, the regression equation is solved to yield estimated mean normal valve size and its $\mathrm{SD}$, from which $Z$ is calculated. ${ }^{15}$

There is a logarithmic relation between indexed and standardized prosthesis-patient size. Standardized size expands the scale of small values compared with indexed values (contrast parts $A$ and $B$ of Figure 5).

\section{Limitations}

Despite the large AVR database used in this analysis, small prosthesis-patient size was rare. Only 28 patients had an indexed orifice area smaller than $0.85 \mathrm{~cm}^{2} / \mathrm{m}^{2}$. Nevertheless, we believe the information about prosthesis-patient size and survival is reliable down to an indexed orifice area of approximately $1.1 \mathrm{~cm}^{2} / \mathrm{m}^{2}$ or 3 SDs below native aortic valve size.

An insurmountable limitation is that neither institution nor valve variety, model, or size was chosen randomly for a given patient. Nonrandom allocation introduces bias. Use of both saturated model techniques and balancing scores provides adjustment for known factors but no explicit protection against factors unavailable across all data sources or unrecorded factors (Appendix 2). ${ }^{11}$

A study like this relies on existing databases that contain a common set of identically defined and relevant variables, similar outcome assessment, and complete reporting. Not all known or purported risk factors for mortality after AVR were available in all data sets. Among the missing variables were ones related to ventricular morphology, measured ventricular function, and noncardiac comorbidities. These variables may not have been distributed uniformly across institutions and may interact with choice of valve prosthesis and size.

All-cause mortality was the end point. It is noninterpretative and was chosen despite the claim that valve-specific mortality is more sensitive. ${ }^{16}$ In fact, reported causes of death are untrustworthy, particularly for elderly patients. ${ }^{8}$ Nevertheless, it is a limitation that we do not know who died suddenly. Although reliable follow-up for survival estimates extended to 15 years, the mean was only 5.3 years. Long-term information requires inclusion of patients operated on in earlier eras, when operative mortality was higher than it is today; we attempted to adjust for this by including date of operation in all analyses.

A strength of this study is representativeness. Databases were solicited from investigators well known for heart valve investigation in North America and Europe and from two organizations responsible for multi-institutional heart valve registries. We also included the spectrum of valve varieties; however, a limitation is the absence of stentless xenografts. Except from one manufacturer, internal orifice size of stentless valves was claimed not to be available, although Rao and colleagues ${ }^{32}$ have reported that the internal orifice size 
of a Toronto stentless prosthesis of labeled size 25 is equivalent to that of a pericardial stented prosthesis of labeled size 21. Allografts were therefore considered to represent stentless devices, despite their use primarily in young and middle-aged patients (only 10\% of recipients were older than 67 years). ${ }^{38}$

\section{Inferences}

Surgical. Within the constraints of prudent AVR in these institutions, we identified no relationship between prosthetic-patient size and intermediate- and long-term survivals. However, we found a small increase in early mortality among patients who received prostheses with small valve orifices in relationship to body size. Although we recognize that outcome after AVR is related to many factors, ${ }^{39}$ with currently available prostheses few patients should require aortic root enlargement with its attendant complexity, prolonged operative time, and risks of bleeding, heart block, and mortality, ${ }^{29}$ particularly if a bioprosthesis is used.

Manufacturing. This study challenges the value of concentrating on better hemodynamic performance. Rather, to improve long-term survival, a durable nonthrombogenic prosthesis is needed that would permit operation much earlier in the natural history of aortic valve disease, before secondary left ventricular remodeling takes place and the patient reports important symptoms.

We thank Tess Knerik for editorial assistance and data managers at each source of information.

\section{References}

1. Rahimtoola SH. The problem of valve prosthesis-patient mismatch. Circulation. 1978;58:20-4.

2. Rahimtoola SH, Murphy E. Valve prosthesis-patient mismatch: a long-term sequela. Br Heart J. 1981;45:331-5.

3. Shepard RB, Simpson DC, Sharp JF. Energy equivalent pressure. Arch Surg. 1966;93:730-40.

4. Berry DA, Stangl DK. Meta-analysis in medicine and health policy. New York: Marcel Dekker; 2000.

5. Christakis GT, Buth KJ, Goldman BS, Fremes SE, Rao V, Cohen G, et al. Inaccurate and misleading valve sizing: a proposed standard for valve size nomenclature. Ann Thorac Surg. 1998;66:1198-203.

6. Kirklin JW, Barratt-Boyes BG. Cardiac surgery. 2nd ed. New York: Churchill Livingstone; 1993.

7. Capps SB, Elkins RC, Fronk DM. Body surface area as a predictor of aortic and pulmonary valve diameter. J Thorac Cardiovasc Surg. 2000;119:975-82.

8. Lauer MS, Blackstone EH, Young JB, Topol EJ. Cause of death in clinical research: time for a reassessment? J Am Coll Cardiol. 1999; 34:618-20.

9. Blackstone EH, Naftel DC, Turner ME Jr. The decomposition of time-varying hazard into phases, each incorporating a separate stream of concomitant information. J Am Stat Assoc. 1986;81:615-24.

10. Steyerberg EW, Eijkemans MJ, Harrell FE Jr, Habbema JD. Prognostic modelling with logistic regression analysis: a comparison of selection and estimation methods in small data sets. Stat Med. 2000;19: 1059-79.

11. Blackstone EH. Comparing apples and oranges. J Thorac Cardiovasc Surg. 2002;123:8-15.
12. Drake C, Fisher L. Prognostic models and the propensity score. Int $J$ Epidemiol. 1995;24:183-7.

13. Blackstone EH. Breaking down barriers: helpful breakthrough statistical methods you need to understand better. J Thorac Cardiovasc Surg. 2001;122:430-9.

14. Breiman L. Bagging predictors. Machine Learning. 1996;26:123-40.

15. Medalion B, Blackstone EH, Lytle BW, White J, Arnold JH, Cosgrove DM. Aortic valve replacement: is valve size important? J Thorac Cardiovasc Surg. 2000;119:963-74.

16. Rao V, Jamieson WR, Ivanov J, Armstrong S, David TE. Prosthesispatient mismatch affects survival after aortic valve replacement. Circulation. 2000;102(19 Suppl 3):III5-9.

17. He GW, Grunkemeier GL, Gately HL, Furnary AP, Starr A. Up to thirty-year survival after aortic valve replacement in the small aortic root. Ann Thorac Surg. 1995;59:1056-62.

18. Hanayama N, Christakis GT, Mallidi HR, Joyner CD, Fremes SE, Morgan CD, et al. Patient prosthesis mismatch is rare after aortic valve replacement: valve size may be irrelevant. Ann Thorac Surg. 2002;73: 1822-9.

19. Frapier JM, Rouviere P, Razcka F, Aymard T, Albat B, Chaptal PA. Influence of patient-prosthesis mismatch on long-term results after aortic valve replacement with a stented bioprosthesis. J Heart Valve Dis. 2002;11:543-51.

20. Pibarot P, Dumesnil JG. Hemodynamic and clinical impact of prosthesis-patient mismatch in the aortic valve position and its prevention. J Am Coll Cardiol. 2000;36:1131-41.

21. Butchart EG, Payne N, Li HH, Buchan K, Mandana K, Grunkemeier GL. Better anticoagulation control improves survival after valve replacement. J Thorac Cardiovasc Surg. 2002;123:715-23.

22. McGiffin DC, O'Brien MF, Galbraith AJ, McLachlan GJ, Stafford EG, Gardner MA, et al. An analysis of risk factors for death and modespecific death after aortic valve replacement with allograft, xenograft, and mechanical valves. J Thorac Cardiovasc Surg. 1993;106:895-911.

23. Izzat MB, Kadir I, Reeves B, Wilde P, Bryan AJ, Angelini GD. Patient-prosthesis mismatch is negligible with modern small-size aortic valve prostheses. Ann Thorac Surg. 1999;68:1657-60.

24. Connolly HM, Oh JK, Schaff HV, Roger VL, Osborn SL, Hodge DO, et al. Severe aortic stenosis with low transvalvular gradient and severe left ventricular dysfunction: result of aortic valve replacement in 52 patients. Circulation. 2000;101:1940-6.

25. Pibarot P, Honos GN, Durand LG, Dumesnil JG. The effect of prosthesis-patient mismatch on aortic bioprosthetic valve hemodynamic performance and patient clinical status. Can J Cardiol. 1996;12:37987.

26. Abdelnoor M, Nitter-Hauge S, Trettli S. Relative survival of patients after heart valve replacement. Eur Heart J. 1990;11:23-8.

27. He GW, Acuff TE, Ryan WH, Douthit MB, Bowman RT, He YH, et al. Aortic valve replacement: determinants of operative mortality. Ann Thorac Surg. 1994;57:1140-6.

28. Morris JJ, Schaff HV, Mullany CJ, Rastogi A, McGregor CG, Daly $\mathrm{RC}$, et al. Determinants of survival and recovery of left ventricular function after aortic valve replacement. Ann Thorac Surg. 1993;56: 22-9.

29. Sommers KE, David TE. Aortic valve replacement with patch enlargement of the aortic annulus. Ann Thorac Surg. 1997;63:1608-12.

30. Castro LJ, Arcidi JM Jr, Fisher AL, Gaudiani VA. Routine enlargement of the small aortic root: a preventive strategy to minimize mismatch. Ann Thorac Surg. 2002;74:31-6.

31. Medalion B, Lytle BW, McCarthy PM, Stewart RW, Arheart KL, Arnold JH, et al. Aortic valve replacement for octogenarians: are small valves bad? Ann Thorac Surg. 1998;66:699-705.

32. Rao V, Christakis GT, Sever J, Fremes SE, Bhatnagar G, Cohen G, et al. A novel comparison of stentless versus stented valves in the small aortic root. J Thorac Cardiovasc Surg. 1999;117:431-6.

33. Blais C, Pibarot P, Dumesnil JG, Garcia D, Chen D, Durand LG. Comparison of valve resistance with effective orifice area regarding flow dependence. Am J Cardiol. 2001;88:45-52.

34. Dumesnil JG, Honos GN, Lemieux M, Beauchemin J. Validation and applications of indexed aortic prosthetic valve areas calculated by Doppler echocardiography. J Am Coll Cardiol. 1990;16:637-43. 
35. Barratt-Boyes BG. The timing of operation in valvular insufficiency. J Card Surg. 1987;2:435-52.

36. Pibarot P, Dumesnil JG, Cartier PC, Metras J, Lemieux MD. Patientprosthesis mismatch can be predicted at the time of operation. Ann Thorac Surg. 2001;71(5 Suppl):S265-8.

37. Rimoldi H, Lev M. A note on the concept of normality and abnormality in quantitation of pathologic findings in congenital heart disease. Pediatr Clin North Am. 1963;10:589-91.

38. Jin XY, Zhang ZM, Gibson DG, Yacoub MH, Pepper JR. Effects of valve substitute on changes in left ventricular function and hypertrophy after aortic valve replacement. Ann Thorac Surg. 1996;62:683-90.

39. Ghosh PK. Small aortic valve prostheses in octogenarians. Ann Thorac Surg. 1999;67:1543-4.

40. Altman DG, Andersen PK. Bootstrap investigation of the stability of a Cox regression model. Stat Med. 1989;8:771-83.

41. Rosenbaum PR, Rubin DB. The central role of the propensity score in observational studies for causal effects. Biometrika. 1983;70:41-55.

42. Adams DH, Chen RH, Kadner A, Aranki SF, Allred EN, Cohn LH. Impact of small prosthetic valve size on operative mortality in elderly patients after aortic valve replacement for aortic stenosis: does gender matter? J Thorac Cardiovasc Surg. 1999;118:815-22.

\section{Appendix 1: Variables Available for Analysis \\ Demographic}

- Age in years as a continuous variable

- Gender

- Height, weight, and BSA in square meters as continuous variables

\section{Clinical Status}

- New York Heart Association functional class (ordinal and as individual classes)

\section{Pathophysiology}

- Aortic stenosis with or without regurgitation

- Aortic regurgitation with or without stenosis

- Pure aortic stenosis

- Pure aortic regurgitation

- Mixed aortic stenosis and regurgitation

\section{Procedure}

- Previous AVR

- Concomitant coronary artery bypass grafting

\section{Experience}

- Date of operation (continuous count of days since January 1, 1969, expressed in years)

- Binary variable representing each source of data

\section{Prosthesis}

- Each prosthesis model as an individual variable

- Prosthesis variety (mechanical, stented bovine pericardial xenograft, stented porcine xenograft, allograft)

\section{Appendix 2: Details of Risk Adjustment \\ Methods}

Scaling. The scales on which to express the continuous variables age, BSA, date of operation, and prosthesis-patient size were suggested by univariable, hazard-phase-specific decile analysis and formalized by bootstrap bagging, selecting those linearizing transformations of scale that appeared with $P<.05$ in $50 \%$ or more of 1000 bootstrap resampling models. ${ }^{13,14,40}$

Selection bias. To adjust for biases in choice of prosthesis size that may have confounded outcome, balancing scores were constructed by linear regression, forcing into each model all available variables (Appendix 1) to predict prosthesis-patient size..$^{41}$ From these regression equations, values for each expression of prosthesis-patient size were predicted for each patient; these predicted values constituted the balancing scores. The balancing score corresponding to each expression of prosthesis-patient size was included as a further adjustment with all other variables in each hazard phase. To illustrate the magnitude of bias between prosthesis size and patient, procedural, and valve variety factors, a logistic regression analysis was performed to identify factors associated with the use of prostheses of labeled size $19 \mathrm{~mm}$ or smaller.

\section{Results}

Risk adjustment. The statistical significance and direction of the association of risk-adjustment variables with survival are presented in Appendix Table 2. Associations include the strong effect of patient factors such as advanced age (Appendix Figure 2), advanced symptoms, aortic regurgitation, previous AVR, and ischemic heart disease. Operative risk was higher earlier in the experience. Small and generally statistically nonsignificant differences in mortality were observed across data sources and among models of aortic prosthesis, with the exception of higher early risk in patients receiving allografts.

Illustration of bias. Compared with other patients, the 1109 who received a prosthesis size $19 \mathrm{~mm}$ or less were older, smaller, more likely to have aortic stenosis, and were more likely to have undergone a previous AVR and concomitant coronary artery bypass grafting (Appendix Table 3).

\section{Appendix 3: Details of Prosthesis-Patient Size Analysis \\ Methods}

Missing values. Sporadic missing values were imputed during analysis by the mean value of nonmissing data. Indicator variables for each variable with missing values were generated and included in regressions that generate balancing scores, and in the saturated multivariable models of survival.

Dichotomous prosthesis-patient size variables. Although we concentrated on continuous measurements, in the multivariable analyses we also examined binary variables for indexed orifice area less than $1.25 \mathrm{~cm}^{2} / \mathrm{m}^{2}$ and standardized orifice size less than $-2.5 \mathrm{Z}$, representing the lowest 10 th percentile of patients, as suggested by Rao and colleagues. ${ }^{16}$

Interactions. After prosthesis-patient size was entered into each hazard phase of the multivariable analyses, assessments of interactions were performed. These included 2-way interactions of patient-prosthesis size with each risk-adjustment variable and 3 -way interactions with age and gender. ${ }^{42}$

\section{Results}

Reliability of findings. Bootstrap bagging with 1000 resampled models was used to assess the reliability of association of prosthesis-patient size with mortality at a significance level of at 
Appendix TABLE 1. Number and internal orifice diameter of each variety and model of prosthesis in study

\begin{tabular}{|c|c|c|c|c|c|c|c|c|c|}
\hline Variety and model & Total & 17 & 19 & 21 & 23 & 25 & 27 & 29 & 31 \\
\hline \multicolumn{10}{|c|}{ Stented porcine xenografts } \\
\hline All (No.) & 5757 & - & 196 & 914 & 1618 & 1656 & 911 & 369 & 93 \\
\hline \multicolumn{10}{|c|}{ Hancock model 242} \\
\hline No. & 1076 & - & 8 & 45 & 142 & 260 & 377 & 193 & 51 \\
\hline Orifice (mm) & & & 16.3 & 18.3 & 20.2 & 22.1 & 22.9 & 24.7 & 26.5 \\
\hline \multicolumn{10}{|c|}{ Hancock model 250} \\
\hline No. & 862 & - & 56 & 205 & 295 & 306 & 0 & 0 & 0 \\
\hline Orifice (mm) & & & 16.3 & 18.3 & 20.2 & 22.1 & & & \\
\hline \multicolumn{10}{|c|}{ Carpentier-Edwards model 2625} \\
\hline No. & 2166 & - & 50 & 324 & 680 & 683 & 293 & 101 & 35 \\
\hline Orifice $(\mathrm{mm})$ & & & 17 & 19 & 21 & 23 & 25 & 27 & 29 \\
\hline \multicolumn{10}{|c|}{ Carpentier-Edwards SAV model 2650} \\
\hline No. & 1653 & - & 82 & 340 & 501 & 407 & 241 & 75 & 7 \\
\hline Orifice (mm) & & & 17 & 19 & 21 & 23 & 25 & 27 & 29 \\
\hline \multicolumn{10}{|c|}{ Stented bovine pericardial bioprostheses } \\
\hline \multicolumn{10}{|c|}{ Carpentier-Edwards PERIMOUNT } \\
\hline No. & 3198 & - & 533 & 1030 & 969 & 498 & 152 & 16 & 0 \\
\hline Orifice $(\mathrm{mm})$ & & & 18 & 20 & 22 & 24 & 26 & 28 & - \\
\hline \multicolumn{10}{|c|}{ Mechanical prostheses } \\
\hline All (No.) & 3583 & 7 & 340 & $922^{*}$ & $1107 \dagger$ & 757 & 325 & 103 & 22 \\
\hline \multicolumn{10}{|c|}{ St Jude Medical, Standard model A-101 } \\
\hline No. & 1992 & - & 297 & 466 & 583 & 388 & 174 & 64 & 20 \\
\hline Orifice (mm) & & & 14.7 & 16.7 & 18.5 & 20.4 & 22.3 & 24.1 & 26.0 \\
\hline \multicolumn{10}{|c|}{ St Jude Medical, Hemodynamic Plus model AHP-105 } \\
\hline No. & 133 & 7 & 43 & 67 & 13 & 3 & - & - & - \\
\hline Orifice (mm) & & & 16.7 & 18.5 & 20.4 & 22.3 & & & \\
\hline \multicolumn{10}{|c|}{ Medtronic Hall model A7700 } \\
\hline No. & 1055 & - & - & $361^{*}$ & $363 \dagger$ & 225 & 80 & 25 & 1 \\
\hline Orifice (mm) & & & & 16 & 18 & 20 & 22 & 24 & 24 \\
\hline \multicolumn{10}{|l|}{ Sorin } \\
\hline No. & 403 & - & - & 28 & 148 & 141 & 71 & 14 & 1 \\
\hline Orifice (mm) & & & & 16 & 18 & 20 & 22 & 24 & 24 \\
\hline Allografts $\ddagger$ (No.) & 721 & 3 & 17 & 67 & 171 & 47 & 12 & 4 & 0 \\
\hline
\end{tabular}

* Of which 136 were labeled size 20 Medtronic Hall prostheses with internal orifice diameter identical to size 21 prostheses. tOf which 35 were labeled size 22 Medtronic Hall prostheses with internal orifice diameter identical to size 23 prostheses. ‡Additional allograft sizes, which are internal orifice diameters, are as follows: $15(n=2), 18(n=11), 20(n=51), 22(n=140), 24(n=165), 26(n=$ $25), 28(n=3)$, and $30(n=2)$.

least $P=.05$. In the early hazard phase, there was a $90 \%$ probability that smaller indexed orifice area was associated with higher mortality, including an $8 \%$ probability that both smaller and larger size were associated. For standardized orifice size, the corresponding probabilities were $90 \%$ and $60 \%$.

In contrast, in the constant hazard phase there was a $20 \%$ probability that smaller indexed orifice area was associated with higher mortality, including a $6 \%$ probability that both smaller and larger size were associated. For standardized orifice size, the corresponding probabilities were $46 \%$ and $4.5 \%$.

In the late hazard phase there was a $25 \%$ probability that smaller indexed orifice area was associated with mortality, including a $2 \%$ probability that both smaller and larger size were associated. For standardized orifice size, the corresponding probabilities were $24 \%$ and $25 \%$.

Search for modulating factors. Interactions between patient factors and expressions of prosthesis-patient size that might modulate these estimates of magnitude of risk were not statistically significant $(P>.1)$. In particular, the pattern of risk in elderly men with aortic stenosis receiving small prostheses was no different from that determined for the entire study group $(P=.9) .{ }^{42}$ Interactions between prosthesis-patient size and valve models did not modulate survival.

\section{Discussion}

Dr David H. Adams (Boston, Mass). Dr Blackstone, I, like most people in the audience, continue to learn from you. By combining a pool of nine multi-institutional databases, you are in a good position to answer some of the important clinical questions associated with aortic valve prosthesis size and operative mortality. Your conclusion that small aortic prostheses increased operative mortality by $1 \%$ in $10 \%$ of patients is statistically elegant. In the manuscript version that I read, you concluded rather strongly that "this study settles the debate about whether smaller aortic prosthesis size in the range used clinically adversely influences 